\title{
Humulus japonicus extract ameliorates collagen-induced arthritis in mice through regulation of overall articular inflammation
}

\author{
EUN-JUNG KANG ${ }^{1}$, HYUN JONG KIM ${ }^{1}$, JI HYUN CHOI $^{1,2}$, JUNG-RAN NOH $^{1}$, JAE-HOON KIM $^{1}$, \\ IN BOK LEE ${ }^{1}$, YOUNG-KEUN CHOI ${ }^{1}$, DONG-HEE CHOI ${ }^{1}$, JINPYO AN $^{3}$, \\ WON KEUN OH ${ }^{3}$, YONG-HOON KIM ${ }^{1,2}$ and CHUL-HO LEE ${ }^{1,2}$ \\ ${ }^{1}$ Laboratory Animal Resource Center, Korea Research Institute of Bioscience and Biotechnology, Daejeon 34141; \\ ${ }^{2}$ Department of Functional Genomics, University of Science and Technology, Daejeon 34113; \\ ${ }^{3}$ Korea Bioactive Natural Material Bank, Research Institute of Pharmaceutical Sciences, \\ College of Pharmacy, Seoul National University, Seoul 08826, Republic of Korea
}

Received May 24, 2019; Accepted November 15, 2019

DOI: $10.3892 /$ ijmm.2019.4417

\begin{abstract}
Humulus japonicus (HJ) is a widely used herbal medicine in Asia with anti-oxidative, anti-microbial, and anti-inflammatory effects. We investigated the potential therapeutic effects of $\mathrm{HJ}$ in rheumatoid arthritis (RA) using a mouse model of collagen-induced arthritis (CIA) and a lipopolysaccharide-stimulated murine macrophage cell line (RAW 264.7). The CIA mice were administered $300 \mathrm{mg} / \mathrm{kg}$ HJ orally starting 3 days prior to second immunization. The clinical and histopathological findings were assessed in the paw of CIA mice. The levels of autoantibodies and inflammatory markers were determined in the plasma and cell culture supernatant, respectively. The expression at mRNA and protein levels was analyzed by reverse transcription quantitative-PCR and western blot analysis, respectively. HJ significantly decreased the gross arthritic scores and paw swelling in CIA mice. Furthermore, synovial inflammation, cartilage destruction, and bone erosion were markedly reduced by HJ. It also decreased the expression of inflammatory enzymes in both the paw of mice and RAW 264.7 cells. Moreover, the expression of genes related to all macrophages and pro-inflammatory M1 macrophage were significantly decreased, whereas the
\end{abstract}

Correspondence to: Dr Yong-Hoon Kim or Dr Chul-Ho Lee, Laboratory Animal Resource Center, Korea Research Institute of Bioscience and Biotechnology, 125 Gwahak-ro, Yuseong-gu, Daejeon 34141, Republic of Korea

E-mail: yhoonkim@kribb.re.kr

E-mail: chullee@kribb.re.kr

Abbreviations: CIA, collagen-induced arthritis; COX, cyclooxygenase; HJ, Humulus japonicas; iNOS, inducible nitric oxide synthase; IL, interleukin; MMPs, metalloproteinases; PGE2, prostaglandin E2; RA, rheumatoid arthritis; TNF- $\alpha$, tumor necrosis factor- $\alpha$

Key words: Humulus japonicus, rheumatoid arthritis, collagen-induced arthritis mice, inflammation, therapy expression of anti-inflammatory M2 macrophage marker was markedly increased in the paw of HJ-treated CIA mice. In addition, HJ suppressed the levels of plasma anti-type II collagen antibody following the decreased expression of $\mathrm{T}$ helper type 1 (Th1) and Th2 cell-associated surface markers and cytokines in the paw. HJ also significantly inhibited the expression of IL- 6 both in vitro and in vivo, followed by reduced STAT3 phosphorylation and expression in the paw of CIA mice. Finally, the expression of osteoclast-related genes was decreased in the paw of HJ-treated CIA mice. These findings suggest that $\mathrm{HJ}$ can play a role in suppressing the development of CIA by overall regulation of articular inflammation. This study should provide new insights into the use of $\mathrm{HJ}$ as a therapeutically effective natural product against RA.

\section{Introduction}

Rheumatoid arthritis (RA) is a chronic, inflammatory, autoimmune disease that primarily affects the joints. In a recent study, it was reported that approximately $0.5-1 \%$ of the world population suffers from RA and the prevalence of this disease is on the increase (1). Although the etiology of RA is not clear, it is believed to be caused by a combination of genetic and environmental factors (2). RA is characterized by chronic joint inflammation, persistent synovial inflammation, progressive cartilage destruction, and bone erosion, leading to painful, stiff, and deformed joints, and joint instability (3). Chronic immune activation results in systemic inflammation as well as in local inflammation within the inflamed joints (3). These systemic inflammatory responses affect extra-articular organs, including those of the gastrointestinal, cardiovascular, and respiratory systems. These non-articular complications of RA are associated with early mortality (4).

Although the mechanism underlying the pathogenesis of RA is not fully understood, both humoral and cellular immunity, including the production of autoantibodies and infiltration of inflammatory cells in the synovium are believed to be involved (5). Autoantibodies produced by plasma cells are involved in the pathogenesis of RA via the formation of immune complexes in the joint (6). Autoantibodies and their 
immune complexes promote the production of pro-inflammatory cytokines via the activation of Fc receptor on macrophages and stimulate the formation of neutrophil extracellular traps leading to inflammatory response in the synovial tissue (7). Furthermore, autoantibodies enhance the differentiation and activation of osteoclasts by directly binding to the osteoclast surface or by indirect induction of pro-inflammatory cytokines, resulting in bone erosion in RA (8). Infiltrating immune cells and synovial fibroblasts produce pro-inflammatory cytokines, such as interleukin (IL)-6, IL-1, tumor necrosis factor- $\alpha$ (TNF- $\alpha$ ), and inflammatory enzymes, including metalloproteinases (MMPs), cyclooxygenase (COX)-2, and inducible nitric oxide (NO) synthase (iNOS). These inflammatory mediators activate genes related to the inflammation response, which is followed by tissue destruction $(9,10)$. In particular, macrophages constitute the major proportion of the cell population in the inflamed synovium and are critically involved in the pathogenesis of RA (11). Macrophages are the major source of pro-inflammatory cytokines and release tissue-degrading enzymes that contribute to inflammation and articular destruction in RA. Increased infiltration of synovial macrophages correlates with the destruction of cartilage and bone (12). Among the pro-inflammatory cytokines, IL-6, which is a pleiotropic cytokine, is produced by various cell types, and regulates the inflammatory response and bone homeostasis in RA (13). The IL-6/IL-6 receptor and gp130 complex can activate the downstream Janus kinase/signal transducer and activator of transcription 3 (JAK/STAT3) signaling pathway (14), and activate osteoclast formation by stimulating the expression of osteoclastogenic genes (15). Abnormal activation of osteoclasts in RA eventually leads to bone resorption and articular bone destruction, one of the major symptoms in RA (16).

Humulus japonicus (HJ), known as 'Japanese hop,' in the family Cannabaceae is an annual vine that originated in countries of East Asia, including China and Korea, and was introduced to North America. The pollen of $\mathrm{HJ}$ is a major cause of allergic rhinitis (17). It is cultivated for use in Asian herbal medicine and has been used to treat pulmonary disease and skin diseases, such as dermatitis, pruritus, and atopic diseases in Korea. Additionally, the anti-oxidative and anti-microbial effects of this plant have been validated $(18,19)$. In a previous study, it was reported that $\mathrm{HJ}$ exerts anti-atherosclerotic effects by inhibiting pro-inflammatory mediators, including NO, prostaglandin E2 (PGE2) and cytokines, such as IL-1 $\beta$, IL-6, and TNF- $\alpha$ (20).

Notwithstanding decades of study, safe and specific medicine for RA has not yet been established. Therefore, there is a need for development of additional new therapeutic agents and discovery of natural plant extracts for the treatment of RA that can suppress joint inflammation and cartilage and bone destruction without adverse effects. These would help in the development of new drugs. Collagen-induced arthritis (CIA) in mice is the most commonly used animal model for RA (21). Generation of self-reactive $T$ cells and antibody-mediated autoimmune reactivity against joint-specific antigen, type II collagen, play an important role in the pathogenesis of CIA (22). CIA mice share histological and immunological features with RA-afflicted humans. The chief shared features include proliferative synovitis with infiltration of immune cells, pannus formation, and erosion of cartilage and bone (23). This model is usually used to assess the therapeutic effects of novel compounds and to study the mechanisms involved in the pathogenesis of RA (21).

In the present study, we examined the anti-arthritic effects of HJ using CIA mice and a murine macrophage cell line.

\section{Materials and methods}

Animal studies. Eight-week-old male DBA/1 mice (Orient Bio Inc.) were acclimatized to a 12 -h light/dark cycle at $22 \pm 2^{\circ} \mathrm{C}$ for 2 weeks with unlimited food and water in a specific pathogen-free facility. The mice were randomly divided into two groups: i) vehicle group $(\mathrm{n}=12)$ treated with $0.5 \%$ carboxymethyl cellulose; ii) HJ group $(n=12)$ treated with $300 \mathrm{mg} / \mathrm{kg}$ of HJ. Starting 3 days before second immunization, $\mathrm{HJ}$ was administered daily by oral gavage for 18 days and changes in body weight were measured each day (Fig. 1A). The humane endpoint for these experiments was set when the mice showed the following clinical signs: Severe paw swelling, severe lameness caused by pain, loss of $\geq 20 \%$ of body weight, or blistering and ulceration at the injection site associated with immunization. There was no animal lost to any of these causes in the present experiments. All the mice were humanely euthanized by $\mathrm{CO}_{2}$ asphyxiation for at least one minute until death confirmed by absence of heart rate, no breathing, and no reflexes. Animal experiments were approved by the Institutional Animal Care and Use Committee of the Korea Research Institute of Bioscience and Biotechnology (KRIBB-AEC-19142) and were performed in accordance with the Guide for the Care and Use of Laboratory Animals published by the US National Institutes of Health (Bethesda).

Preparation of HJ extract. HJ was purchased from Gangwon Herbs, Gangwon, Republic of Korea, on July, 2014. Professor W.K. Oh identified the voucher specimen (SNU-2014-0004), which was then deposited at the College of Pharmacy, Seoul National University, Korea. The HJ extract was prepared and supplied by the Korea Bioactive Natural Material Bank (Seoul). Briefly, the dried aerial parts of HJ were soaked in $70 \%$ ethanol in an extraction container for 2 days at room temperature.

Cell culture. Murine macrophage RAW 264.7 cells were purchased from the American Type Cell Culture (ATCC; Manassas). The cells were cultured in Dulbecco's modified Eagle's medium (DMEM; Hyclone; GE Healthcare Life Sciences) containing 10\% fetal bovine serum (FBS; Gibco, Thermo Fisher Scientific, Inc.), $100 \mathrm{U} / \mathrm{ml}$ penicillin, and $100 \mu \mathrm{g} / \mathrm{ml}$ streptomycin, in a humidified environment $\left(5 \% \mathrm{CO}_{2} / 95 \%\right.$ air) at $37^{\circ} \mathrm{C}$. The cells were pre-treated with different concentrations of $\mathrm{HJ}(50,100,200 \mu \mathrm{g} / \mathrm{ml})$ for $1 \mathrm{~h}$ and were subsequently stimulated with lipopolysaccharide (LPS, $0.4 \mu \mathrm{g} / \mathrm{ml}$; Sigma) or vehicle for $24 \mathrm{~h}$.

Induction and clinical assessment of CIA. For induction of arthritis, bovine type II collagen (Chondrex) was dissolved at $2 \mathrm{mg} / \mathrm{ml}$ in phosphate-buffered saline containing $0.1 \mathrm{M}$ acetic acid, and was emulsified in an equal volume of $2 \mathrm{mg} / \mathrm{ml}$ 

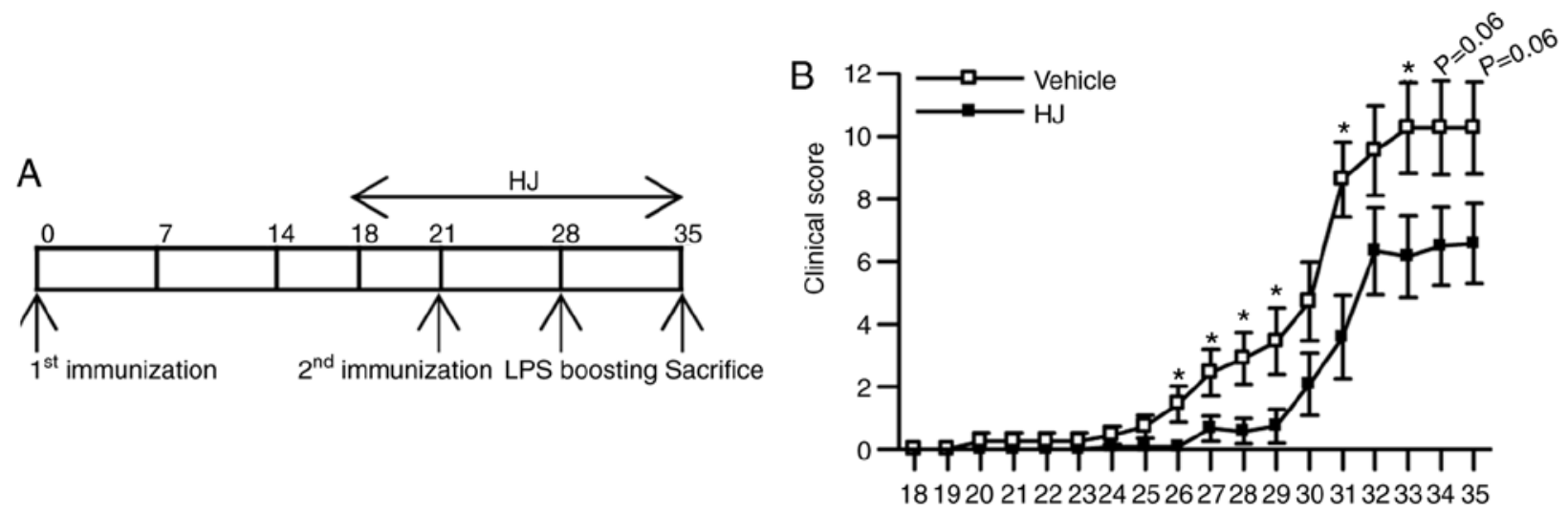

Day after 1 st immunization
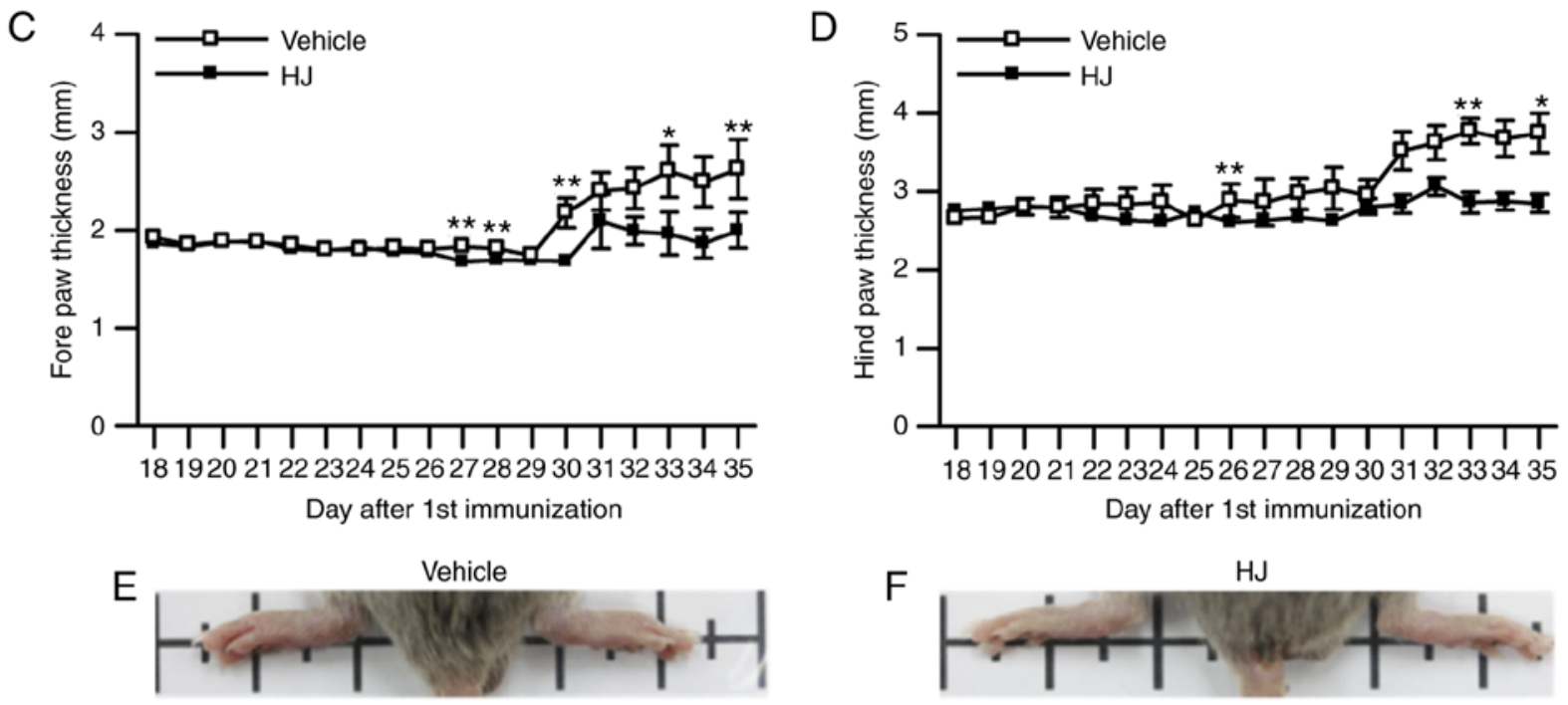

Figure 1. Alleviation of the development and progression of collagen-induced arthritis by administration of Humulus japonicus (HJ). (A) Schematic representation of immunization and HJ administration. (B) Severity of arthritis in collagen-induced arthritis (CIA) mice was evaluated by determining the clinical arthritis score from 4 day prior to the second immunization. Diameter of the (C) fore paws and (D) rear paws of mice was measured with a caliper from 4 day before the second immunization. Representative images of rear paws of (E) vehicle-treated mice and (F) HJ-treated mice on the last day of the experiment. Grouped quantitative data are presented as means \pm SEM (vehicle group; $n=11$, HJ group; $n=12$ ). (B-D) Two-way ANOVA followed by Wilcoxon test were used to compare the results of the vehicle and HJ groups; ${ }^{*} \mathrm{P}<0.05,{ }^{* *} \mathrm{P}<0.01$.

complete Freund's adjuvant (Chondrex). Mice were immunized intradermally at the base of the tail with $100 \mu \mathrm{l}$ emulsion containing $100 \mu \mathrm{g}$ bovine type II collagen. After 21 days, a booster dose was administered intradermally in the same way as described above. Seven days after the second immunization, the animals were boosted with an intraperitoneal injection of $40 \mu \mathrm{g}$ LPS. The mice were examined for paw swelling and a clinical score was determined. Paw swelling was assessed through measuring the mean thickness of all the paws with a micrometer caliper. The clinical score was assessed using the following system: 0 , normal paw; 1 , one toe inflamed and swollen; $2,>1$ toe, but not the entire paw, inflamed and swollen, or mild swelling of the entire paw; 3 , entire paw inflamed and swollen; 4, very inflamed and swollen or ankylosed paw (24). Each limb was graded, giving a maximum possible score of 16 per animal.

Histopathological analysis. The rear paws from each mouse were collected on day 35 of first immunization. The paws were fixed, decalcified, paraffin-embedded, sectioned $(5 \mu \mathrm{m})$, and stained with hematoxylin and eosin (H\&E), safranin $\mathrm{O}$, or toluidine blue. The H\&E sections were analyzed microscopically for the degree of inflammation and for cartilage and bone destruction, using the following scale: 0 , normal synovium; 1 , synovial membrane hypertrophy and cell infiltrates; 2 , pannus and cartilage erosion; 3 , major erosion of cartilage and subchondral bone; 4, loss of joint integrity and ankyloses (25). Synovitis was evaluated by H\&E staining and was scored according to the following scale: 0 , no inflammation; 1 , slight thickening of the lining layer or some infiltrating cells in the underlying layer; 2 , slight thickening of the lining layer plus some infiltrating cells in the underlying layer; 3 , thickening of the lining layer, an influx of cells in the underlying layer, and the presence of cells in the synovial space; 4 , highly infiltrated synovium, with many inflammatory cells (26). Representative images of the histopathological grading system are shown in Fig. 2A and B.

Reverse transcription quantitative-polymerase chain reaction. Total RNA was isolated from the fore paw using TRIzol reagent (Invitrogen), and reverse transcribed using the iScript ${ }^{\mathrm{TM}}$ cDNA Synthesis kit (Bio-Rad) with a primer annealing step at $25^{\circ} \mathrm{C}$ for $5 \mathrm{~min}$, followed by reverse transcrip- 
tion at $46^{\circ} \mathrm{C}$ for $20 \mathrm{~min}$, inactivation at $95^{\circ} \mathrm{C}$ for $1 \mathrm{~min}$, and storage at $4^{\circ} \mathrm{C}$. The resulting cDNA was subjected to qPCR using the StepOnePlus ${ }^{\mathrm{TM}}$ Real-Time PCR System (Applied Biosystems) with AccuPower ${ }^{\circledR} 2 \mathrm{X}$ Greenstar qPCR Master Mix (Bioneer), according to the manufacturers' protocol. The cycling conditions were $95^{\circ} \mathrm{C}$ for $10 \mathrm{~min}$, followed by 40 cycles of $95^{\circ} \mathrm{C}$ for $10 \mathrm{sec}$, and $60^{\circ} \mathrm{C}$ for $1 \mathrm{~min}$. To detect and remove possible primer-dimer artifacts, a dissociation curve was generated for the following cycling conditions: $95^{\circ} \mathrm{C}$ for 15 $\mathrm{sec}, 60^{\circ} \mathrm{C}$ for $1 \mathrm{~min}$, and $95^{\circ} \mathrm{C}$ for $15 \mathrm{sec}$. Relative gene expression levels were analyzed using the $2^{-\Delta \Delta \mathrm{Cq}}$ method (27) and normalized against the expression of 18S rRNA. The primer sequences used in the experiments are listed in Table I.

Measurement of serum anti-type II collagen antibody $\operatorname{Ig} G$, IgG1, and IgG2a by ELISA. Plasma samples were collected at the end of the experiment (day 35) for the determination of IgG, IgG1, and IgG2a antibody levels with three commercially available test kits, mouse anti-mouse Type II collagen IgG TMB (2036T, Chondrex), IgG1 TMB (20361T, Chondrex), and IgG2a (20362T, Chondrex) antibody subtype assay kit TMB, according to the manufacturer's instructions. Antibody levels were quantified using seven standard serum samples (0.16-10 ng/ml).

Measurement of nitrite, PGE2 production, and IL-6 secretion in the LPS-stimulated RAW264.7 cells. The level of nitrite was measured in the culture supernatant from the LPS-stimulated RAW 264.7 cells using a NO estimation kit, according to the manufacturer's instructions (Intron). The NO estimation kit is based on the principle of diazotization (Griess method) technique. The levels of PGE2 and IL-6 in the culture supernatant were measured via competitive PGE2 ELISA kit (ENZO Life Sciences) and BD OptEIA ${ }^{\mathrm{TM}}$ Set (BD Biosciences), respectively, according to the manufacturers' instructions.

Western blot analysis. The paws from the DBA/1 mice were collected at the end of the experiment (day 35). Paws and RAW264.7 cells were prepared by homogenization in a RIPA lysis buffer containing 1\% NP-40, $0.25 \%$ sodium deoxycholate, $50 \mathrm{mmol} / 1$ Tris- $\mathrm{HCl} \mathrm{pH} 7.4,1 \mathrm{mmol} / 1$ EDTA and $120 \mathrm{mmol} / 1 \mathrm{NaCl}$ added with the protease and phosphatase inhibitors. Centrifugation was carried out three times at $12,000 \mathrm{x} \mathrm{g}$ for $10 \mathrm{~min}$ at $4^{\circ} \mathrm{C}$ and the protein concentration in the supernatant was measured using the Bradford method. Protein samples were separated by electrophoresis on $10 \%$ sodium dodecyl sulfate-polyacrylamide gel and transferred onto a polyvinylidene fluoride membrane (Millipore). The membranes were blocked with $5 \%$ skimmed milk in Tris-buffered saline-Tween $0.1 \%$ for $30 \mathrm{~min}$ at room temperature. The membranes were incubated with the primary antibodies specific to COX-2 (1:100 dilution; ab15191; Abcam), iNOS (1:100 dilution; ab49999; Abcam), p-STAT3 Ser727 (1:100 dilution; CST9134; Cell Signaling), and STAT3 (1:100 dilution; CST9139; Cell Signaling) at $4^{\circ} \mathrm{C}$ overnight prior to application of HRP-conjugated secondary antibodies (1:1,000 dilution) for $1 \mathrm{~h}$ at room temperature. After washing with Tris-buffered saline and Tween-20, bands were detected using EzWestLumi plus (ATTO). TINA software, 2.09 (Raytest Isotopenmessgeräte) was used for measuring density of western blot bands. The ratio was determined in arbitrary units.

Statistical analysis. Numerical data are presented as means \pm SEM. Comparisons between two groups were performed using a two-tailed Student's t-test. Comparisons among multiple groups were performed using Tukey-Kramer HSD test after one-way ANOVA or Wilcoxon test after two-way ANOVA. The threshold of significance was set at $\mathrm{P}<0.05$.

\section{Results}

HJ treatment ameliorates CIA in mice. DBA/1 mice were immunized on days 0 and 21 with bovine type II collagen and were treated with HJ orally starting 3 days prior to the second immunization, as detailed in the methods section (Fig. 1A). The gross score of paw arthritis was significantly reduced from day 26 to day 29, and showed a trend toward a decrease from day 30 to the last day of the experiment following the first immunization in the HJ group compared to that in the vehicle group (Fig. 1B). Paw edema was evaluated by measuring the paw thickness from the first day of treatment with vehicle or HJ until the end of the experiment. Mice in the HJ group showed a significant reduction in the size of hind paw (3.29 \pm 0.18 vs. $2.70 \pm 0.14 \mathrm{~mm}$ for vehicle versus $\mathrm{HJ}$ group) as well as of forepaw $(2.36 \pm 0.16$ vs. $1.75 \pm 0.14 \mathrm{~mm}$ for vehicle versus HJ group) at the end of the experiment (Fig. 1C and D). In agreement with paw diameter, development of swelling or redness of paw was diminished in the hind paws in HJ group (Fig. 1E and F). These results demonstrated that HJ has ameliorative effects on CIA.

$H J$ reduces articular inflammation and injury in CIA mice. The severity of arthritis in CIA mice was also evaluated by H\&E staining of histological sections of mouse hind paw. The mice in the vehicle group showed histopathological changes typical of RA, including synovial hypertrophy with massive infiltration of inflammatory cells and erosion of bone and cartilage (Fig. 2C). By contrast, mice in the HJ group showed a marked reduction in the infiltration of inflammatory cells and less erosion of bone and cartilage (Fig. 2C). In agreement with the results of H\&E staining, histological and synovitis scores were significantly diminished in $\mathrm{HJ}$-treated mice compared to those in vehicle-treated mice (Fig. 2D and E). The reduction in cartilage damage was further confirmed by safranin $\mathrm{O}$ and toluidine blue staining in the HJ group (Fig. 2F and G). Based on these results, it could be suggested that $\mathrm{HJ}$ improves CIA via the regulation of synovial inflammation, cartilage damage, and bone erosion.

$H J$ inhibits the expression of pro-inflammatory mediators in the paw of CIA mice and LPS-stimulated RAW264.7 cells. We conducted RT-qPCR to determine whether HJ inhibits the expression of inflammation-related proteases and enzymes in the paw of CIA mice. The expression levels of Mmp3, Mmp13, Cox-2, and $i N O S$ were significantly reduced in the paw of HJ-treated mice compared to the levels in vehicle-treated mice (Fig. 3A-D). As macrophages play a crucial role in RA by expressing inflammatory mediators, such as iNOS, COX-2, 

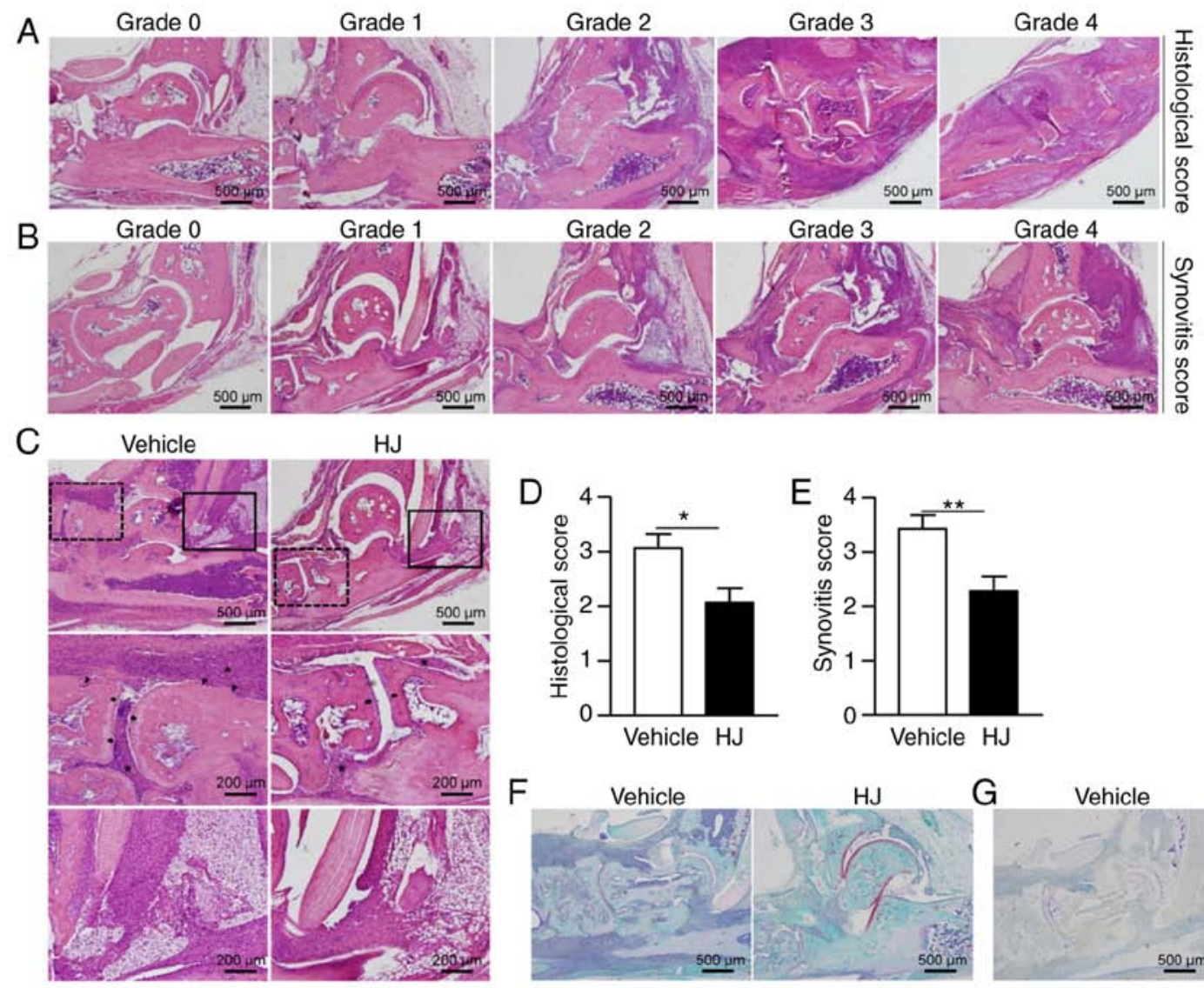

Figure 2. Effect of Humulus japonicus on synovial inflammatory changes and cartilage destruction. On day 35, following the first immunization, paws were obtained from all collagen-induced arthritis (CIA) mice treated either with the vehicle or HJ. (A and B) Representative hematoxylin and eosin (H\&E) staining images of the scoring indices in the paw of CIA mice. (A) The histological score for articular inflammation and destruction of cartilage and bone. (B) The degree for synovitis. (C) Representative images of the paw of CIA mice stained with H\&E. Middle panels show enlarged views of the region within a box with solid line in the upper panels in each group. Lower panels show enlarged view of the region within a box with dashed line in the upper panels in each group. Annotations: inflammatory cell infiltration (asterisk), bone resorption (arrowhead), and cartilage destruction (arrow). (D) Histopathological scoring of H\&E-stained tissue. (E) Synovial inflammation scoring of H\&E-stained tissue. (F and G) Representative images of paws stained with (F) safranin O or (G) toluidine blue. Grouped quantitative data are presented as means \pm SEM (vehicle group; $n=15$, HJ group; $n=15$ ). Wilcoxon test was used to compare the results of the vehicle and $\mathrm{HJ}$ groups; ${ }^{*} \mathrm{P}<0.05,{ }^{* *} \mathrm{P}<0.01$.

and MMPs $(9,28)$, we investigated whether HJ suppresses the expression of inflammatory mediators in LPS-stimulated RAW 264.7 cells. The mRNA expression of Mmp3, Mmp13, Cox-2, and $i N O S$ were markedly decreased after HJ treatment in a dose-dependent manner (Fig. 3E-H). In addition to the reduced expression of these genes, western blot analysis revealed that the protein levels of Cox-2 and iNOS were also decreased in a dose-dependent manner after HJ treatment compared with their levels in cells treated with LPS only (Fig. 3I). Furthermore, the secretion levels of PGE2 and NO produced by Cox-2 and iNOS, respectively, were significantly decreased in HJ-treated cells compared to the levels in cells treated only with LPS in a dose-dependent manner (Fig. 3J and K). These results suggest that $\mathrm{HJ}$ downregulates the induction of inflammatory mediators under both in vitro and in vivo inflamed situations.

HJ reduces articular macrophage infiltration in CIA. The degree of synovial macrophage infiltration correlates with the severity of RA (29). Monocytes can differentiate into classically activated pro-inflammatory M1 macrophages to aggravate the RA symptom and alternatively into anti-inflammatory M2 macrophages to improve the RA phenotype (30). Therefore, we determined whether $\mathrm{HJ}$ influences the infiltration of articular macrophages and the M1/M2 subsets in CIA mice. The gene expression levels of $C d 68$ as pan-macrophage marker, and $C d 11 c, C d 80$, and $C d 86$ as M1 macrophage markers were significantly reduced in paws of the HJ group compared to the levels in the vehicle group (Fig. 4A-D). By contrast, the expression level of M2 macrophage marker, Cd163 and the arginase $1 /$ iNOS ratio were significantly increased in the paws of mice in the HJ group suggesting skewing from classically to alternatively activated macrophages (Fig. 4E and F) (31). These results suggest that $\mathrm{HJ}$ reduces the infiltration of macrophages and affects the M1/M2 subsets in the paw of CIA mice.

HJ inhibits autoantibody production in CIA mice. We further investigated as to how $\mathrm{HJ}$ improves inflammatory arthritis in CIA mice. Anti-collagen autoantibodies have pathogenic properties in the RA and IgG2a has a critical role in the development of RA (32). Therefore, we investigated whether $\mathrm{HJ}$ inhibits the production of collagen-specific antibody and affects humoral immunity in CIA mice. To confirm this, we measured the level of type II collagen-specific total IgG, IgG1, and $\operatorname{IgG} 2 \mathrm{a}$ in the plasma of CIA mice by ELISA. The levels 
Table I. PCR primer sequences used in this study.

\begin{tabular}{|c|c|c|}
\hline Gene & Gene bank accession no. & Primer sequence \\
\hline \multirow[t]{2}{*}{ Mmp3 } & NM_010809.2 & Forward 5'-GCCATCTCTTCCATCCAACA-3' \\
\hline & & Reverse 5'-CCAGGGTGTGAATGCTTTTA-3' \\
\hline \multirow[t]{2}{*}{ Mmpl3 } & NM_008607.2 & Forward 5'-GGAGCCACAGATGAGCACAGA-3' \\
\hline & & Reverse 5'-TGAACGCTCGCAGTGAAAAG-3' \\
\hline \multirow[t]{2}{*}{$\operatorname{Cox}-2$} & NM_011198.4 & Forward 5'-GGGTGTCCCTTCACTTCTTTCA-3' \\
\hline & & Reverse 5'-GAGTGGGAGGCACTTGCATT-3' \\
\hline \multirow[t]{2}{*}{$i N O S$} & NM_001313921.1 & Forward 5'-GTTCTCAGCCCAACAATACAAGA-3' \\
\hline & & Reverse 5'-GTGGACGGGTCGATGTCAC-3' \\
\hline \multirow[t]{2}{*}{ Cd68 } & NM_001291058.1 & Forward 5'-TCACAGTTCACACCAGCTCC-3' \\
\hline & & Reverse 5'-CTTGGACCTTGGACTAGGCG-3' \\
\hline \multirow[t]{2}{*}{$C d 11 c$} & NM_001363984.1 & Forward 5'-CTGGATAGCCTTTCTTCTGCTG-3' \\
\hline & & Reverse 5'-GCACACTGTGTCCGAACTCA-3' \\
\hline \multirow[t]{2}{*}{$C d 80$} & NM_001359898.1 & Forward 5'-ACCCCCAACATAACTGAGTCT-3' \\
\hline & & Reverse 5'-TTCCAACCAAGAGAAGCGAGG-3' \\
\hline \multirow[t]{2}{*}{$C d 86$} & NM_019388.3 & Forward 5'-TCTTCCTCTGTTCCTTGGGC-3' \\
\hline & & Reverse 5'-TGCGGCTCCCTGTGTGT-3' \\
\hline \multirow[t]{2}{*}{$C d 163$} & NM_001170395.1 & Forward 5'-GGTGGACACAGAATGGTTCTT-3' \\
\hline & & Reverse 5'-CCAGGAGCGTTAGTGACAGC-3' \\
\hline \multirow[t]{2}{*}{ Arginase 1} & NM_007482.3 & Forward 5'-ACATTGGCTTGCGAGACGTA-3' \\
\hline & & Reverse 5'-ATCACCTTGCCAATCCCCAG-3' \\
\hline \multirow[t]{2}{*}{$I l-12 r \beta 1$} & NM_001311141.1 & Forward 5'-CTGCACCCACTCACATTAAC-3' \\
\hline & & Reverse 5'-CAGTTGGCTTTGCCCTGTGG-3' \\
\hline \multirow[t]{2}{*}{ Ccr2 } & NM_009915.2 & Forward 5'-GGGCTGTGAGGCTCATCTTT-3' \\
\hline & & Reverse 5'-TGCATGGCCTGGTCTAAGTG-3' \\
\hline \multirow[t]{2}{*}{ Ccr5 } & NM_009917.5 & Forward 5'-CGAAAACACATGGTCAAACG-3' \\
\hline & & Reverse 5'-GTTCTCCTGTGGATCGGGTA-3' \\
\hline \multirow[t]{2}{*}{ Ccr3 } & NM_009914.4 & Forward 5'-TGCTGAGATGTCCCAATA-3' \\
\hline & & Reverse 5'-GCCAGGTCCAGATGTTTA-3' \\
\hline \multirow[t]{2}{*}{ Ccr4 } & NM_009916.2 & Forward 5'-GGAAGGTATCAAGGCATTTGGG-3' \\
\hline & & Reverse 5'-GTACACGTCCGTCATGGACTT-3' \\
\hline \multirow[t]{2}{*}{$I l-2$} & NM_008366.3 & Forward 5'-CTGGAGCAGCTGTTGATGGA-3' \\
\hline & & Reverse 5'-GCCTGCTTGGGCAAGTAAAA-3' \\
\hline \multirow[t]{2}{*}{ Il-13 } & NM_008355.3 & Forward 5'-ATTGCAATGCCATCTACAGG-3' \\
\hline & & Reverse 5'-TTGCTTTGTGTAGCTGAGCA-3' \\
\hline \multirow[t]{2}{*}{$I l-6$} & NM_031168.2 & Forward 5'-TTCCATCCAGTTGCCTTCTTG-3' \\
\hline & & Reverse 5'-GGGAGTGGTATCCTCTGTGAAGTC-3' \\
\hline \multirow[t]{2}{*}{ Rank } & NM_009399.3 & Forward 5'-AGAGGGGAGCCTCAGGGTCC-3' \\
\hline & & Reverse 5'-AAGTTCATCACCTGCCCGCTAGA-3' \\
\hline \multirow[t]{2}{*}{ Nfatcl } & NM_001164111.1 & Forward 5'-GCCTCGAACCCTATCGAGTG-3' \\
\hline & & Reverse 5'-AGTTATGGCCAGACAGCACC-3' \\
\hline \multirow[t]{2}{*}{$C t s K$} & NM_007802.4 & Forward 5'-TACCCATATGTGGGCCAGGA-3' \\
\hline & & Reverse 5'-TTCAGGGCTTTCTCGTTCCC-3' \\
\hline \multirow[t]{2}{*}{ Trap } & NM_001102405.1 & Forward 5'-GGAACTTCCCCAGCCCTTAC-3' \\
\hline & & Reverse 5'-AGGTCTCGAGGCATTTTGGG-3' \\
\hline Oscar & NM_001290377.1 & Forward 5'-GTAACGGATCAGCTCCCCAG-3' \\
\hline & & Reverse 5'-TGCAAAACTCATGCCCGGTA-3' \\
\hline Calr & NM_007588.2 & Forward 5'-TAGTTAGTGCTCCTCGGGCT-3' \\
\hline & & Reverse 5'-AGTACTCTCCTCGCCTTCGT-3' \\
\hline $18 s$ rRNA & NR_003278.3 & Forward5'-GACACGGACAGGATTGACAGATTGATAG-3 \\
\hline & & Reverse 5'-GTTAGCATGCCAGAGTCTCGTTCGTT-3' \\
\hline
\end{tabular}


A
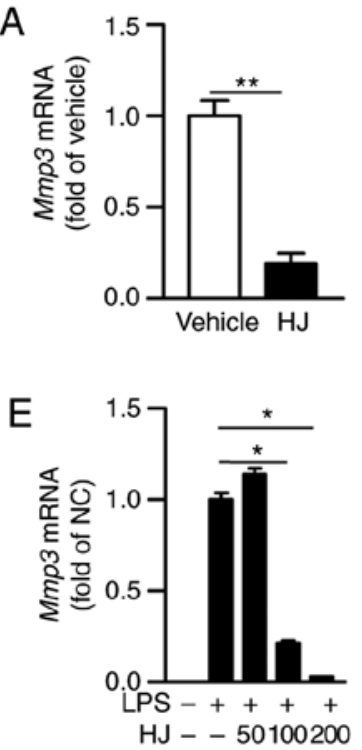
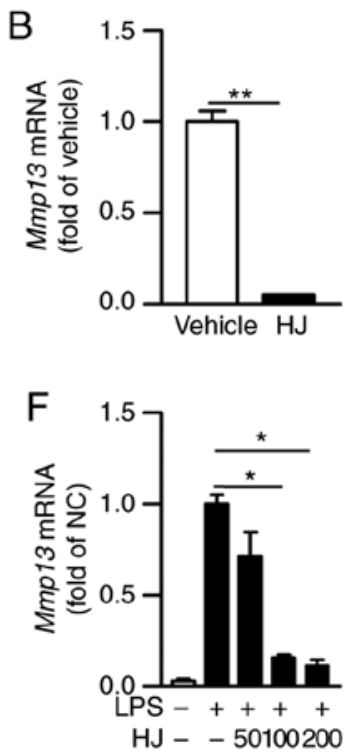
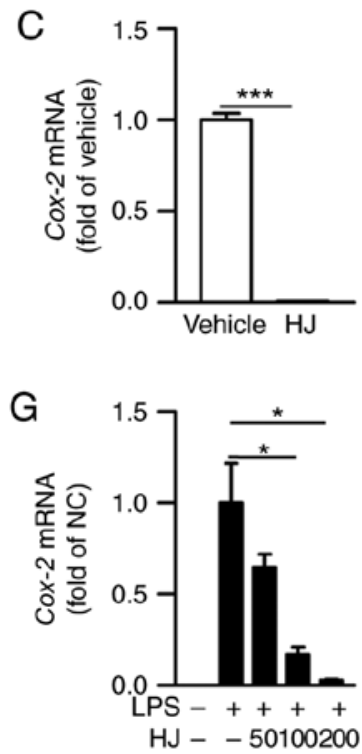
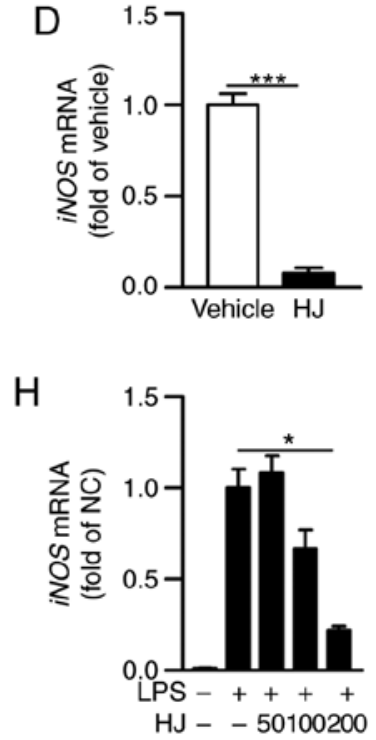

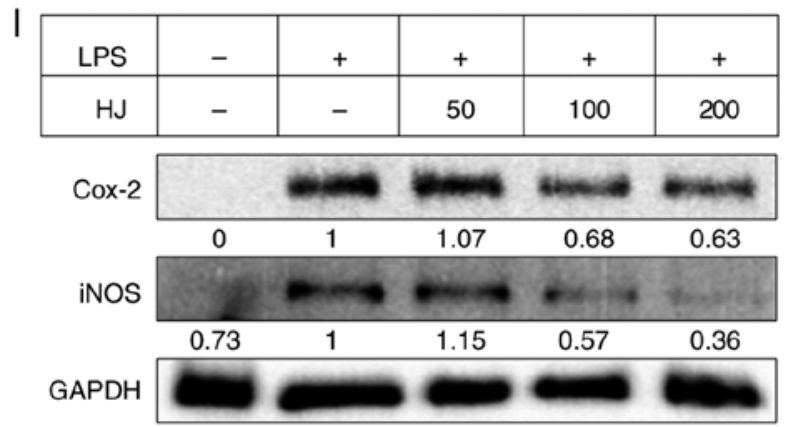

\section{J}
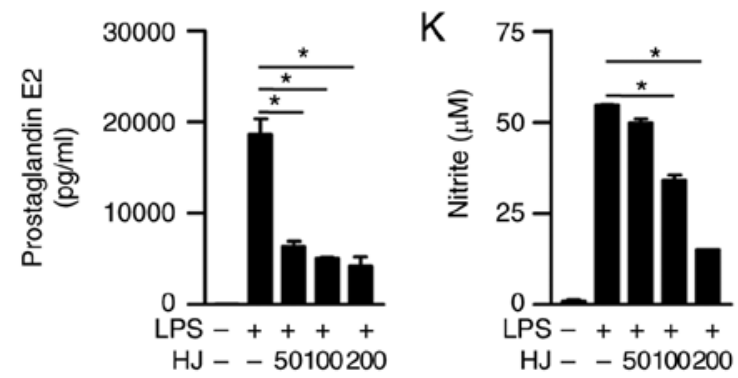

Figure 3. Regulatory effect of Humulus japonicus on pro-inflammatory enzymes in collagen-induced arthritis (CIA) mice and lipopolysaccharide (LPS)-stimulated RAW 264.7 cells. (A-D) Gene expression levels of Mmp3 (A), Mmp13 (B), Cox-2 (C), and iNOS (D) were analyzed by RT-qPCR in the paw of CIA mice on the last day of the experiment. The vehicle group was set to a value of 1, and average fold-change is shown. (E-K) RAW 264.7 cells were pre-treated with different concentrations of $\mathrm{HJ}(0-200 \mu \mathrm{g} / \mathrm{ml})$ for $1 \mathrm{~h}$ and were stimulated with $0.4 \mu \mathrm{g} / \mathrm{ml} \mathrm{LPS}$ or vehicle for $24 \mathrm{~h}$. Gene expression levels of (E) Mmp3, (F) Mmp13, (G) Cox-2 and (H) iNOS in the RAW264.7 cell lysate were analyzed by RT-qPCR. The LPS-only treated group (normal control) was set to a value of 1, and average fold-change is shown. (I) Protein levels of COX-2 and iNOS in the RAW264.7 cell lysate were identified by western blot analysis. Band intensities were quantified and normalized relative to the quantity of their respective GAPDH bands, and expressed as fold changes of the values in the LPS-only treated group. ( $\mathrm{J}$ and $\mathrm{K}$ ) Levels of (J) prostaglandin E2 (PGE2) and (K) nitric oxide (NO) were evaluated in the RAW264.7 cell culture supernatant by ELISA and Griess test, respectively. Representative data from at least three independent experiments are shown. Grouped quantitative data are presented as means \pm SEM (vehicle group; $n=8$, HJ group; $n=6$ ). Significance was measured using (A-D) two-tailed Student's t-test or (E-K) the Tukey-Kramer HSD test following one-way ANOVA. ${ }^{*} \mathrm{P}<0.05,{ }^{* *} \mathrm{P}<0.01,{ }^{* * *} \mathrm{P}<0.001$.

of total IgG specific to type II collagen were not significantly different between the vehicle and the HJ group (Fig. 5A). The production of collagen-specific IgG2a was significantly reduced in the $\mathrm{HJ}$ group compared to that in the vehicle group and a trend toward reduced IgG1 was also observed in the HJ group (Fig. 5B and C). The production of $\mathrm{IgG} 2 \mathrm{a}$ is induced by T-helper type 1 (Th1) cell-derived cytokines, such as IFN- $\gamma$ and IL-2, and production of IgG1 is associated with Th2 cell-dependent cytokines, such as IL-4 and IL-13 (33). We next investigated whether $\mathrm{HJ}$ could regulate the $\mathrm{Th} 1$ and $\mathrm{Th} 2$ cells in the paw of CIA mice. The expression levels of $I L-12 r \beta 2$, $C c r 2$, and $C c r 5$ as Th1 cell-associated surface markers and $\mathrm{Ccr} 3$ and $\mathrm{Ccr} 4$ as $\mathrm{Th} 2$ cell-related surface markers were significantly reduced in the paw of mice in the HJ group compared to those in the vehicle group mice (Fig. 5D-H). Furthermore, the expression levels of Th1 cytokine, $I L-2$, and Th2 cytokine, $I L-13$, were markedly decreased in the paw of HJ-treated mice (Fig. 5I and J). From these results, it is clear that HJ improves CIA via downregulation of the Th1- and Th2-mediated autoantibody production.

HJ suppresses the expression of IL-6 and inhibits STAT3 signaling pathways in CIA mice. IL-6 is one of the most abundantly expressed cytokines in the rheumatoid synovium and has critical roles in the inflammatory process and osteoclast-mediated bone resorption in RA (34). The expression level of $I L-6$ was significantly reduced in a dose-dependent manner in LPS-stimulated RAW 264. 7 cells treated with HJ compared to that in cells treated only with LPS (Fig. 6A). The secretion level of IL- 6 was also significantly reduced in the supernatant of HJ-treated cells compared to that in cells treated only with LPS in a dose-dependent manner, although the differences among $\mathrm{HJ}$ concentration were not significant (Fig. 6B). Moreover, the expression of $I L-6$ was markedly decreased in the paw mice in the $\mathrm{HJ}$ group compared to that in mice of the vehicle group (Fig. 6C). IL-6 transduces signals 

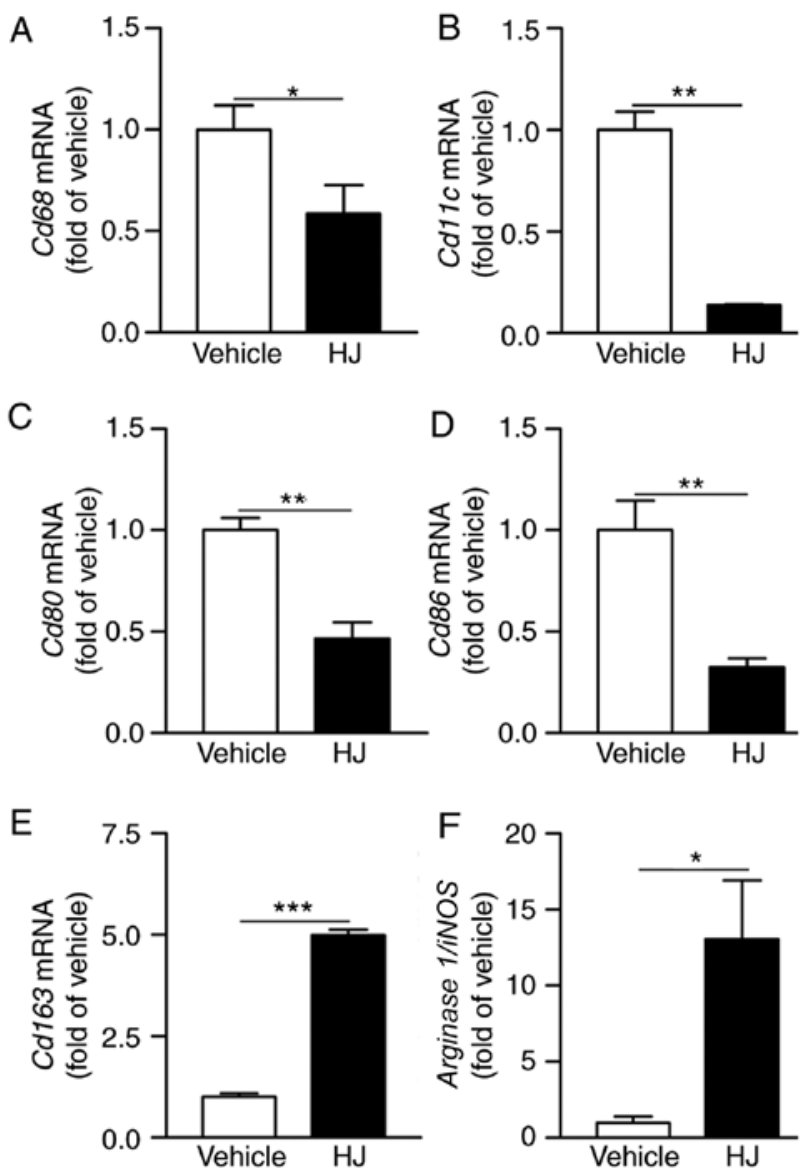

Figure 4. Influence of Humulus japonicus $(\mathrm{HJ})$ on the macrophage infiltration and M1/M2 differentiation in collagen-induced arthritis (CIA) mice. The gene expression levels of (A) Cd68, (B) Cd11c, (C) Cd80, (D) Cd86, (E) $C d 163$ and (F) the arginase/iNOS ratio were analyzed by RT-qPCR in the paw of CIA mice on day 35 following the first immunization. Grouped quantitative data are presented as means \pm SEM (vehicle group; $n=8, H J$ group; $n=6)$. Significance was measured using the two-tailed Student's t-test. ${ }^{*} \mathrm{P}<0.05,{ }^{* *} \mathrm{P}<0.01,{ }^{* * *} \mathrm{P}<0.001$.

via the phosphorylation of STAT3, and STAT3 stimulates joint inflammation and erosion in RA (35). Treatment with HJ significantly reduced the phosphorylation and expression of STAT3 in paw of CIA mice (Fig. 6D). Taken together, these results suggest that $\mathrm{HJ}$ downregulates the expression of IL-6 and STAT3 signaling pathway in the paw of CIA mice.

HJ ameliorates CIA through inhibition of osteoclast-specific genes and expression of transcription factors. Considering that periarticular bone erosions and generalized bone loss are hallmarks of RA and that osteoclasts play a critical role in bone erosion (36), we analyzed osteoclastogenesis-related gene expression in the paw of CIA mice. In the HJ group mice, the expression levels of Rank and an osteoclastogenic transcription factor, $N$ fatcl, were decreased compared to that in the vehicle group (Fig. 7A and B). HJ treatment markedly reduced the expression of osteoclast-specific genes, including Ctsk, Trap, Calr, and Oscar, in the paw of CIA mice, albeit the reduction in the expression of the latter two genes was not statistically significant (Fig. 7C-F). These results suggest that $\mathrm{HJ}$ can ameliorate CIA via inhibition of the induction of osteoclast-related genes.

\section{Discussion}

Previous findings have shown that $\mathrm{HJ}$ has anti-atherosclerotic and anti-inflammatory effects by inhibiting pro-inflammatory cytokines, including TNF- $\alpha$, IL-1 $\beta$, and IL-6, and inflammatory mediators, including $\mathrm{COX}-2$ and iNOS, in the LPS-stimulated RAW264.7 macrophage cells (20). In addition, HJ exerts inhibitory effects on LPS-induced phosphorylation of the inhibitor $\kappa \mathrm{B}-\alpha(37)$. However, there are no reports on the therapeutic potential of HJ against RA. In the present study, we demonstrated the anti-arthritic effect of $\mathrm{HJ}$, in vitro and in vivo. $\mathrm{HJ}$ effectively ameliorated the rheumatic symptoms by inhibiting inflammation and articular destruction as revealed by diminished gross and histological arthritic score.

RA is a systemic inflammatory disorder and is characterized by increased levels of pro-inflammatory cytokines, such as TNF $\alpha$ and IL-6, in the plasma, and of pro-inflammatory enzymes, including MMPs, COX-2, and iNOS, in the synovium, which contribute to articular inflammation, bone erosion, and cartilage destruction $(9,10)$. Moreover, MMPs secreted by synovial fibroblasts, chondrocytes, and macrophages contribute to degradation of the extracellular matrix in the articular cartilage (38). Among them, MMP3 and MMP13 are considered important pathological mediators of RA (38). MMP3 can degrade a different extracellular matrix such as aggrecan and fibronectin in joint, and also activate other MMPs such as pro-MMP1 and pro-MMP13 (39). In addition, MMP13 plays a crucial role in cleaving type II collagen, which is a major component of the cartilage and also cleaves other cartilage collagen types, such as types IX and X, and other extracellular matrix components including fibronectin and aggrecan (40). Moreover, in RA, COX-2 and iNOS induced by activated macrophage are responsible for the production of PGE2 and NO, respectively. The overproduction of PGE2 and $\mathrm{NO}$ play key roles in RA and are involved in pain, inflammation, and tissue destruction (41). In the present study, HJ significantly inhibited the expression of pro-inflammatory cytokine, $I L-6$, and pro-inflammatory enzymes, such as Mmp3, Mmp13, Cox-2, and iNOS, in a dose-dependent manner after HJ treatment in LPS-stimulated RAW264.7 cells and in the paw of CIA mice. However, a limitation of this study was that we could not measure the levels of MMP13, COX-2, and iNOS by ELISA in the plasma of CIA mice. Instead, we measured alternatively the levels of PGE2 and NO produced by COX-2 and iNOS, respectively, in the HJ-treated Raw264.7 cell culture supernatant after LPS stimulation. In accordance with the gene expression levels of Cox-2 and $i N O S$, HJ reduced the protein levels of COX-2 and iNOS and also reduced the production levels of PGE2 and NO in a dose-dependent manner. These results suggest that $\mathrm{HJ}$ can ameliorate CIA by suppressing pro-inflammatory cytokine and enzymes.

In addition to the regulation of the expression of inflammatory mediators in macrophages, $\mathrm{HJ}$ also markedly reduced the expression of the pan-macrophage marker and M1 macrophage marker, whereas the expression of M2 macrophage marker and the arginase $1 /$ iNOS ratio were significantly increased in the paw of HJ-treated CIA mice. The degree of macrophage infiltration and activation correlates, not only with joint pain and inflammation, but also with joint erosion in RA. A number of macrophages are present in the inflamed 

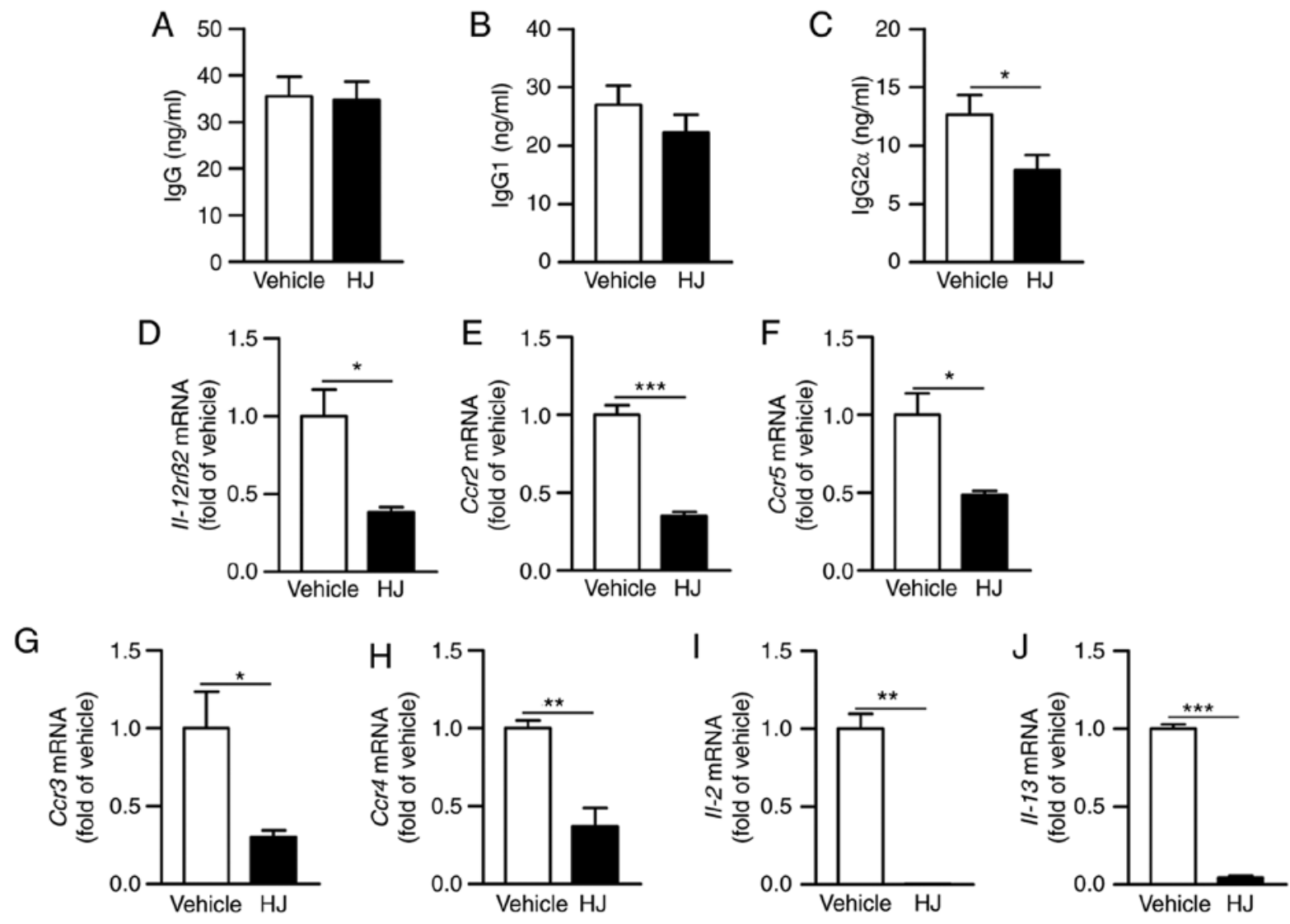

Figure 5. Effect of Humulus japonicas (HJ) on the production of anti-type II collagen antibody in plasma. Levels of (A) anti-type II collagen total IgG and its subtypes (B) IgG1, and (C) IgG2a were measured by ELISA in plasma obtained on day 35 from each mice group. Gene expression levels of (D) $I l-12 r \beta 2$, (E) $C c r 2$, (F) $C c r 5$, (G) $C c r 3$, (H) $C c r 4$, (I) $I L-2$ and (J) $I L-13$ were analyzed by RT-qPCR in the paw of CIA mice on day 35 following the first immunization. The vehicle group was set to a value of 1 , and average fold-change is shown. Grouped quantitative data are presented as means \pm SEM (vehicle group; $n=8$, HJ group; $\mathrm{n}=6$ ). Significance was measured using two-tailed Student's t-test. ${ }^{*} \mathrm{P}<0.05,{ }^{* *} \mathrm{P}<0.01,{ }^{* * *} \mathrm{P}<0.001$.
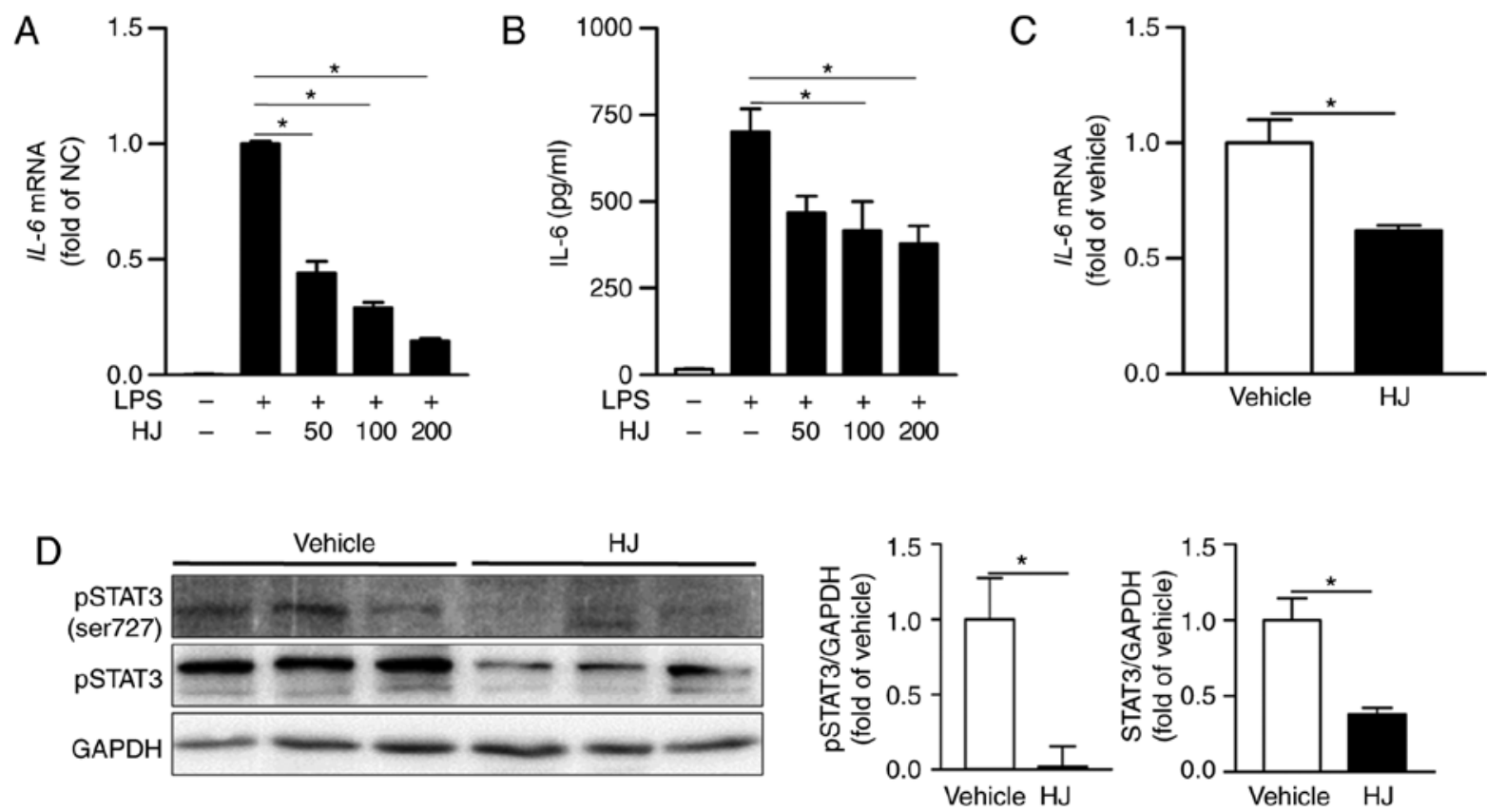

Figure 6. Regulatory effect on expression of IL-6 and STAT3 signaling pathway by Humulus japonicus (HJ) in collagen-induced arthritis (CIA) mice. (A and B) RAW264.7 cells were pre-treated with different concentrations of $\mathrm{HJ}(0-200 \mu \mathrm{g} / \mathrm{ml})$ or vehicle for $1 \mathrm{~h}$ and stimulated with $0.4 \mu \mathrm{g} / \mathrm{ml} \mathrm{LPS} \mathrm{for} 12 \mathrm{~h}$. (A) The gene expression level of $I L-6$ was analyzed by RT-qPCR in RAW264.7 cell lysate. (B) Secretion level of IL-6 was measured by ELISA in RAW264.7 cell culture supernatant. Representative data from at least three independent experiments are shown. (C and D) The gene expression of $I L-6$ was analyzed by RTq-PCR and protein levels of (C) pSTAT3 and (D) STAT3 were analyzed by western blot analysis in the paw of CIA mice on day 35 following the first immunization. Grouped quantitative data are presented as means \pm SEM (vehicle group; $n=8, H J$ group; $n=6$ ). Significance was measured using the Tukey-Kramer HSD test following (A and B) one-way ANOVA or by (C and D) two-tailed Student's t-test. "P<0.05. 

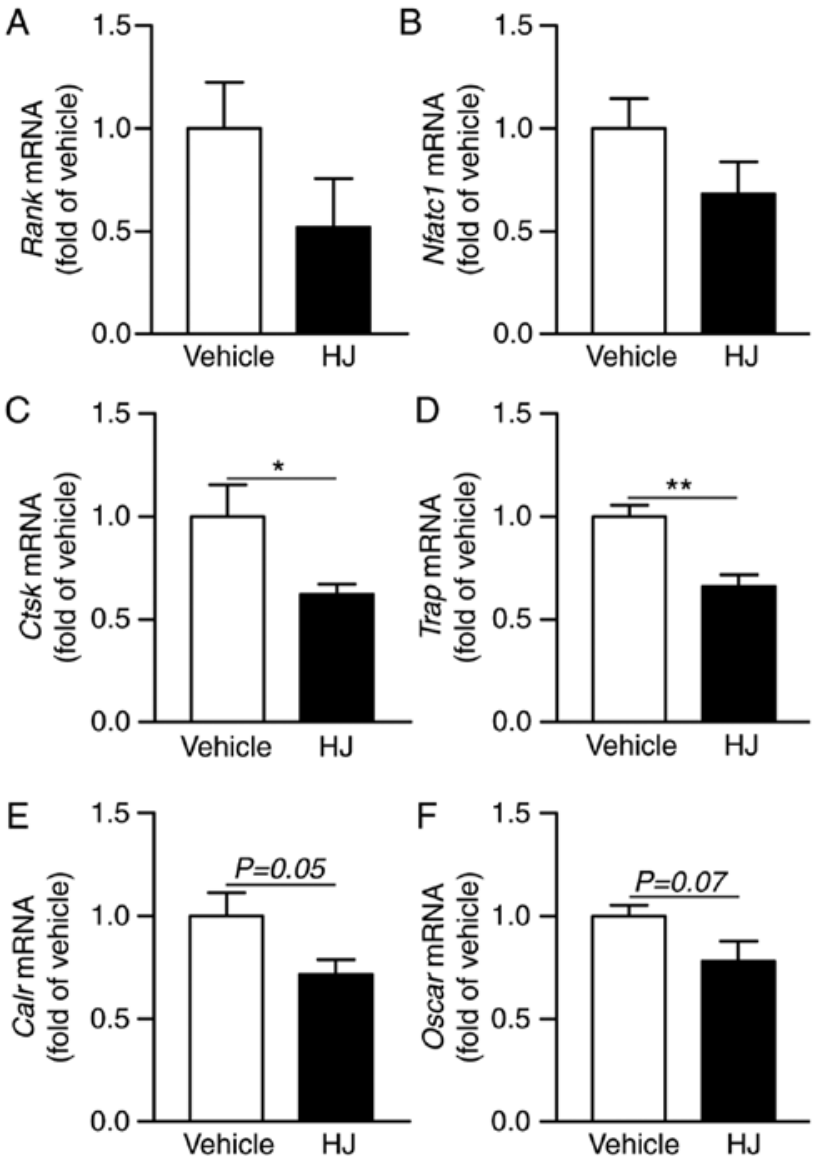

Figure 7. Effects of Humulus japonicas (HJ) treatment on gene expression of osteoclast activity markers in collagen-induced arthritis (CIA) mice. On day 35, following the first immunization, paws were obtained from all CIA mice treated either with vehicle or HJ. Gene expression levels of (A) Rank (osteoclast surface receptor), (B) Nfatcl (master transcription factor for osteoclastogenesis), and osteoclast-specific markers, including (C) Ctsk, (D) Trap, (E) Calr, and (F) Oscar, were analyzed by RT-qPCR. Vehicle group was set to a value of 1, and the average fold-change is shown. Grouped quantitative data are presented as means \pm SEM (vehicle group; $n=8$, HJ group; $\mathrm{n}=6$ ). Two-tailed Student's t-test was used to compare vehicle group with $\mathrm{HJ}$ group. ${ }^{*} \mathrm{P}<0.05,{ }^{* *} \mathrm{P}<0.01$.

synovium and play important roles in the pathogenesis of RA by releasing various cytokines, chemokines, and MMP leading to the erosion of cartilage and bone (11). Monocytes can differentiate into classically activated pro-inflammatory M1 macrophage or alternatively activated anti-inflammatory M2 macrophage. M1 macrophages, activated by LPS- or Th1-related cytokines, such as interferon- $\gamma$, produce various pro-inflammatory cytokines resulting in tissue damage in the development of RA (42). On the other hand, M2 macrophages activated by Th2-related cytokines, including IL-4 and IL-13, are involved in tissue remodeling by producing anti-inflammatory cytokines (28). In other words, an imbalance in the $\mathrm{M} 1 / \mathrm{M} 2$ ratio is associated with the development of RA. These findings suggest that the reduction of macrophage infiltration and improvement of M1/M2 ratio in the joints of CIA mice may attenuate CIA by decreasing the inflammatory mediators in the paw of HJ-treated mice. However, further studies are needed to understand the manner in which $\mathrm{HJ}$ regulates macrophage migration and M1/M2 differentiation in the paw of CIA mice.
RA is an autoimmune disease characterized by increased production of autoantibodies (7). Cytokines derived from $\mathrm{T}$ cells stimulate the differentiation and proliferation of B cells into plasma cells and enhance the production of autoantibody in RA (43). Th1 cytokines, IFN- $\gamma$ and IL-2, induce class switching to $\mathrm{IgG} 2 \mathrm{a}$ and are associated with cellular immunity, whereas Th2 cytokines, IL-4 and IL-13, regulate the switch from IgM/D to IgG1 and IgE and are associated with humoral immunity (44). Thus, the balance between Th1 and Th2 cells regulates the antibody-mediated immune response, and RA is described as a Th1-dominant chronic autoimmune disease (45). In the present study, we found that $\mathrm{HJ}$ significantly suppressed the production of anti-type II collagen-specific IgG2a, and tended to reduce the production of anti-type II collagen-specific IgG1. Even though we did not analyze T-cell subsets via flow cytometric analysis in the paw of CIA mice, we additionally measured gene expression levels of $I l-12 r \beta 2, C c r 2$ and $C c r 5$ as Th1 cell-associated markers, and $C c r 3$ and $C c r 4$ as Th2 cell-associated markers in the paw of HJ-treated CIA mice. HJ markedly decreased the expression levels of Th1 and Th2 cell surface markers in the paws of CIA mice. In accordance with these changes, the gene expression levels of Th1 and Th 2 cytokines, $I L-2$ and $I L-13$, were also markedly reduced in the paws of CIA mice. These results demonstrate that the HJ inhibits the production of autoantibodies, especially Th1-mediated IgG2a, by downregulating both Th1 and Th2 cells and cytokines in the CIA mice. However, further investigation is required to elaborate the regulatory effect of $\mathrm{HJ}$ on $\mathrm{Th} 1$ and $\mathrm{Th} 2$ cell differentiation and B cell-derived autoantibody production in collagen-specific humoral immunity.

Among the cytokines, IL-6, derived from synovial fibroblasts and activated macrophages are critical in the pathogenesis of RA. IL-6 contributes to synovial inflammation by recruiting inflammatory cells and can also promote the production of autoantibody acting on plasma blasts, which leads to destruction of the cartilage (46). This cytokine is also the major STAT3-activating factor in RA and IL-6-mediated STAT3 is involved in the destruction of joints through stimulation of the expression of RANKL in osteoblasts and the induction of osteoclast differentiation (47). Osteoclasts are terminally differentiated cells of the monocyte/macrophage lineage that resorb the bone matrix. Periarticular bone erosion adjacent to the inflamed joint and systemic bone loss are characteristic features of RA (48). The destruction of bones in RA is mainly attributable to the abnormal activation of osteoclasts (49). The production of autoantibody and pro-inflammatory cytokine-driven infiltrating immune cells in the synovium stimulate the differentiation of bone resorbing osteoclasts, thereby contributing to bone erosion (50). Pro-inflammatory cytokines promote osteoclastogenesis via the expression of RANKL on the surface of osteoblasts (51). Some researchers have shown that pro-inflammatory cytokines, including TNF- $\alpha$, IL-1 $\beta$, and IL-6, are capable of inducing osteoclast differentiation independently of RANKL (52). In the present study, HJ significantly reduced the expression and secretion levels of IL-6 in LPS-simulated RAW264.7 macrophage cells and in the paw of CIA mice. Furthermore, phosphorylated STAT3 and total STAT3 were significantly reduced in the HJ group compared to that in the vehicle group. Additionally, $\mathrm{HJ}$ reduced the expression of osteoclast-specific markers, 
including Ctsk, Trap, Calr, and Oscar, as well as of the transcription factor, NFATcl. Therefore, these results suggest that $\mathrm{HJ}$ modulates the activation of osteoclasts via regulation of the expression of IL-6 and STAT3 signaling pathways in the paws of CIA mice. Although STAT3 is the major downstream signaling pathway of IL-6, further investigation is needed to determine whether HJ modulates the IL- 6 expression in a STAT3 signaling pathway-dependent manner in CIA.

In conclusion, to the best of our knowledge, this is the first study to suggest that $\mathrm{HJ}$ has protective effects on the inflammation and destruction of cartilage and bones during the development of RA in CIA mice by inhibiting the secretion of pro-inflammatory mediators and osteoclast formation. The results of the present study provide novel insights into the possibility of using $\mathrm{HJ}$ extract as therapeutics for preventing RA.

\section{Acknowledgements}

The authors would like to thank Mrs. Y.J. Seo and Mrs. J.H. Choi (Laboratory Animal Resource Center, Korea Research Institute of Bioscience and Biotechnology, Daejeon, Republic of Korea) for their technical assistance.

\section{Funding}

This study was supported by grants from the KRIBB Research Initiative Program, a grant from the National Research Foundation of Korea (NRF) and the Korean government (MSIP) (NRF-2019R1C1C1005319), and the Korea Bioactive Natural Material Bank (KBNMB, NRF-2017M3A9B8069409) through the National Research Foundation of Korea, funded by the Ministry of Science, ICT and Planning.

\section{Availability of data and materials}

The datasets generated during the present study are not currently available to the public but will be available from the corresponding author on reasonable request.

\section{Authors' contributions}

EJK, HJK, YHK and CHL designed the experiments and the study. EJK, HJK, JHC, JRN, JHK, IBL, YKC, DHC and JA collected data and conducted experiments for the study. EJK, HJK, YHK and CHL analyzed all the data. WKO and CHL contributed to critical revisions of the text. All authors read and approved the final manuscript.

\section{Ethics approval and consent to participate}

All animal experiments were approved by the Institutional AnimalCare and Use Committee of the Korea Research Institute of Bioscience and Biotechnology (KRIBB-AEC-19142) and were performed in accordance with the Guide for the Care and Use of Laboratory Animals published by the US National Institutes of Health.

\section{Patient consent for publication}

Not applicable.

\section{Competing interests}

The authors declare no competing of interest.

\section{References}

1. Myasoedova E, Crowson CS, Kremers HM, Therneau TM and Gabriel SE: Is the incidence of rheumatoid arthritis rising?: Results from Olmsted County, Minnesota, 1955-2007. Arthritis Rheum 62: 1576-1582, 2010.

2. Silman AJ and Pearson JE: Epidemiology and genetics of rheumatoid arthritis. Arthritis Res 4 (Suppl 3): S265-S272, 2002.

3. Heidari B: Rheumatoid Arthritis: Early diagnosis and treatment outcomes. Caspian J Intern Med 2: 161-170, 2011.

4. Cojocaru M, Cojocaru IM, Silosi I, Vrabie CD and Tanasescu R: Extra-articular manifestations in rheumatoid arthritis. Maedica (Buchar) 5: 286-291, 2010.

5. Guo Q, Wang Y, Xu D, Nossent J, Pavlos NJ and Xu J: Rheumatoid arthritis: Pathological mechanisms and modern pharmacologic therapies. Bone Res 6: 15, 2018.

6. Suurmond J, Zou YR, Kim SJ and Diamond B: Therapeutics to block autoantibody initiation and propagation in systemic lupus erythematosus and rheumatoid arthritis. Sci Transl Med 7: 280ps285, 2015.

7. Derksen VFAM, Huizinga TWJ and van der Woude D: The role of autoantibodies in the pathophysiology of rheumatoid arthritis. Semin Immunopathol 39: 437-446, 2017.

8. Bugatti S, Manzo A, Montecucco C and Caporali R: The clinical value of autoantibodies in rheumatoid arthritis. Front Med (Lausanne) 5: 339, 2018.

9. Bingham CO III: The pathogenesis of rheumatoid arthritis: Pivotal cytokines involved in bone degradation and inflammation. J Rheumatol Suppl 65: 3-9, 2002.

10. Choy E: Understanding the dynamics: Pathways involved in the pathogenesis of rheumatoid arthritis. Rheumatology (Oxford) 51 (Suppl 5): v3-v11, 2012.

11. Kinne RW, Stuhlmüller B and Burmester GR: Cells of the synovium in rheumatoid arthritis. Macrophages. Arthritis Res Ther 9: 224, 2007.

12. Ma Y and Pope RM: The role of macrophages in rheumatoid arthritis. Curr Pharm Des 11: 569-580, 2005.

13. Pablos Álvarez JL: Interleukin 6 in the physiopathology of rheumatoid arthritis. Reumatol Clin 5: 34-39, 2009 (In Spanish).

14. Blanchard F, Duplomb L, Baud'huin M and Brounais B: The dual role of IL-6-type cytokines on bone remodeling and bone tumors. Cytokine Growth Factor Rev 20: 19-28, 2009.

15. Kwan Tat S, Padrines M, Théoleyre S, Heymann D and Fortun Y: IL-6, RANKL, TNF-alpha/IL-1: Interrelations in bone resorption pathophysiology. Cytokine Growth Factor Rev 15: 49-60, 2004.

16. Weitzmann MN: The role of inflammatory cytokines, the RANKL/OPG axis, and the immunoskeletal interface in physiological bone turnover and osteoporosis. Scientifica (Cairo) 2013: 125705, 2013.

17. Park JW, Ko SH, Kim CW, Jeoung BJ and Hong CS: Identification and characterization of the major allergen of the Humulus japonicus pollen. Clin Exp Allergy 29: 1080-1086, 1999.

18. Sung B, Chung JW, Bae HR, Choi JS, Kim CM and Kim ND: Humulus japonicus extract exhibits antioxidative and anti-aging effects via modulation of the AMPK-SIRT1 pathway. Exp Ther Med 9: 1819-1826, 2015 (In Korean).

19. Park SW, Woo CJ, Chung SK and Chung KT: Antimicrobial and antioxidative activities of solvent fraction from Humulus japonicas. Korean J Food Sci Technol 26: 464-470, 1994.

20. Lim H, Noh JR, Kim YH, Hwang JH, Kim KS, Choi DH, Go MJ, Han SS, Oh WK and Lee CH: Anti-atherogenic effect of Humulus japonicus in apolipoprotein E-deficient mice. Int J Mol Med 38: 1101-1110, 2016.

21. Brand DD, Latham KA and Rosloniec EF: Collagen-induced arthritis. Nat Protoc 2: 1269-1275, 2007.

22. Nandakumar KS, Bäcklund J, Vestberg M and Holmdahl R: Collagen type II (CII)-specific antibodies induce arthritis in the absence of T or B cells but the arthritis progression is enhanced by CII-reactive T cells. Arthritis Res Ther 6: R544-R550, 2004.

23. Brand DD, Kang AH and Rosloniec EF: The mouse model of collagen-induced arthritis. Methods Mol Med 102: 295-312, 2004.

24. Lee CH, Bae SJ and Kim M: Mucosa-associated lymphoid tissue lymphoma translocation 1 as a novel therapeutic target for rheumatoid arthritis. Sci Rep 7: 11889, 2017. 
25. Sun J, Jia Y, Li R, Guo J, Sun X, Liu Y, Li Y, Yao H, Liu X, Zhao J and $\mathrm{Li} \mathrm{Z}$ : Altered influenza virus haemagglutinin (HA)-derived peptide is potent therapy for CIA by inducing Th1 to Th2 shift. Cell Mol Immunol 8: 348-358, 2011.

26. Jhun JY, Yoon BY, Park MK, Oh HJ, Byun JK, Lee SY, Min JK, Park SH, Kim HY and Cho ML: Obesity aggravates the joint inflammation in a collagen-induced arthritis model through deviation to Th17 differentiation. Exp Mol Med 44: 424-431, 2012

27. Livak KJ and Schmittgen TD: Analysis of relative gene expression data using real-time quantitative PCR and the 2(-Delta Delta C(T)) Method. Methods 25: 402-408, 2001.

28. Laria A, Lurati A, Marrazza M, Mazzocchi D, Re KA and Scarpellini M: The macrophages in rheumatic diseases. J Inflamm Res 9: 1-11, 2016.

29. Kinne RW, Bräuer R, Stuhlmüller B, Palombo-Kinne E and Burmester GR: Macrophages in rheumatoid arthritis. Arthritis Res 2: 189-202, 2000

30. Fukui S, Iwamoto N, Takatani A, Igawa T, Shimizu T, Umeda M, Nishino A, Horai Y, Hirai Y, Koga T, et al: M1 and M2 monocytes in rheumatoid arthritis: A contribution of imbalance of M1/M2 monocytes to osteoclastogenesis. Front Immunol 8: 1958, 2018.

31. Munder M, Eichmann K and Modolell M: Alternative metabolic states in murine macrophages reflected by the nitric oxide synthase/arginase balance: Competitive regulation by CD4+ $\mathrm{T}$ cells correlates with Th1/Th2 phenotype. J Immunol 160 $5347-5354,1998$

32. Mukherjee P, Wu B, Mayton L, Kim SH, Robbins PD and Wooley PH: TNF receptor gene therapy results in suppression of IgG2a anticollagen antibody in collagen induced arthritis. Ann Rheum Dis 62: 707-714, 2003.

33. Corry DB and Kheradmand F: Induction and regulation of the IgE response. Nature 402: B18-B23, 1999.

34. Srirangan S and Choy EH: The role of interleukin 6 in the pathophysiology of rheumatoid arthritis. Ther Adv Musculoskelet Dis 2: $247-256,2010$.

35. Oike T, Sato Y, Kobayashi T, Miyamoto K, Nakamura S, Kaneko Y, Kobayashi S, Harato K, Saya H, Matsumoto M, et al: Stat3 as a potential therapeutic target for rheumatoid arthritis. Sci Rep 7: 10965, 2017

36. Rehman Q and Lane NE: Bone loss. Therapeutic approaches for preventing bone loss in inflammatory arthritis. Arthritis Res 3: 221-227, 2001

37. Hwang SY, Jo MJ, Kim SC and Jee SY: Anti-inflammaory effects of the $\mathrm{MeOH}$ extract of Humulus japonicus in vivo. J Korean Orient Med Ophthalmol Otolaryngol Dermatol 22: 92-103, 2009.

38. Burrage PS, Mix KS and Brinckerhoff CE: Matrix metalloproteinases: Role in arthritis. Front Biosci 11: 529-543, 2006

39. Lerner A, Neidhöfer S, Reuter S and Matthias T: MMP3 is a reliable marker for disease activity, radiological monitoring, disease outcome predictability, and therapeutic response in rheumatoid arthritis. Best Pract Res Clin Rheumatol 32: 550-562, 2018.
40. Rose BJ and Kooyman DL: A tale of two joints: The role of matrix metalloproteases in cartilage biology. Dis Markers 2016: 4895050, 2016

41. Amin AR, Attur M and Abramson SB: Nitric oxide synthase and cyclooxygenases: Distribution, regulation, and intervention in arthritis. Curr Opin Rheumatol 11: 202-209, 1999.

42. Wang Y, Han CC, Cui D, Li Y, Ma Y and Wei W: Is macrophage polarization important in rheumatoid arthritis? Int Immunopharmacol 50: 345-352, 2017.

43. Cope AP, Schulze-Koops H and Aringer M: The central role of T cells in rheumatoid arthritis. Clin Exp Rheumatol 25: S4-S11, 2007.

44. Kaplan C, Valdez JC, Chandrasekaran R, Eibel H, Mikecz K, Glant TT and Finnegan A: Th1 and Th2 cytokines regulate proteoglycan-specific autoantibody isotypes and arthritis. Arthritis Res 4: 54-58, 2002.

45. Aarvak T, Chabaud M, Thoen J, Miossec P and Natvig JB: Changes in the Th1 or Th 2 cytokine dominance in the synovium of rheumatoid arthritis (RA): A kinetic study of the Th subsets in one unusual RA patient. Rheumatology (Oxford) 39: 513-522, 2000.

46. Yoshida Y and Tanaka T: Interleukin 6 and rheumatoid arthritis. Biomed Res Int 2014: 698313, 2014.

47. Yoshitake F, Itoh S, Narita H, Ishihara K and Ebisu S: Interleukin-6 directly inhibits osteoclast differentiation by suppressing receptor activator of NF-kappaB signaling pathways. J Biol Chem 283: 11535-11540, 2008.

48. Panagopoulos PK and Lambrou GI: Bone erosions in rheumatoid arthritis: Recent developments in pathogenesis and therapeutic implications. J Musculoskelet Neuronal Interact 18: 304-319, 2018.

49. Sato K and Takayanagi H: Osteoclasts, rheumatoid arthritis, and osteoimmunology. Curr Opin Rheumatol 18: 419-426, 2006.

50. Schett $\mathrm{G}$ and Gravallese E: Bone erosion in rheumatoid arthritis: Mechanisms, diagnosis and treatment. Nat Rev Rheumatol 8: 656-664, 2012

51. Jung SM, Kim KW, Yang CW, Park SH and Ju JH: Cytokine-mediated bone destruction in rheumatoid arthritis. J Immunol Res 2014: 263625, 2014.

52. Lieben L: Bone: The concept of RANKL-independent osteoclastogenesis refuted. Nat Rev Rheumatol 12: 623, 2016.

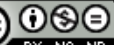

This work is licensed under a Creative Commons Attribution-NonCommercial-NoDerivatives 4.0 International (CC BY-NC-ND 4.0) License. 